\title{
Proposal of a New Descriptive-Correlational Model of Population Lifestyle Analysis and Disease Diagnosis
}

\author{
Selene Tamayo Castro ${ }^{1, *}$, Kristian Aldapa Salcido ${ }^{1}$, Linda García Rodríguez ${ }^{2}$ \\ ${ }^{1}$ Business Planning and Regional Development, Tecnológico Nacional de México, Instituto/I.T. de Los Mochis, 81200, México
}

${ }^{2}$ Strategic Planning and Technology Management, Tecnológico Nacional de México, Instituto/ I.T. de Los Mochis, 81200, México

\begin{tabular}{l} 
A R T I C L E I N F O \\
\hline Article history: \\
Received: 10 September, 2020 \\
Accepted: 07 October, 2020 \\
Online: 20 November, 2020 \\
\hline Keywords: \\
Strategic planning \\
Disruptive innovation \\
Lifestyle \\
Chronic diseases \\
\hline
\end{tabular}

\begin{abstract}
A B S T R A C T
This document proposes a new methodology for lifestyle analysis and disease diagnosis for young academics using a strategic planning and disruptive innovation approach. Its objective is to consider and study a new form of treatment to improve the quality of life and health of students in parallel with their development, this through a quantitative methodology with a descriptive-correlational scope, being possible to develop a diagnosis and analysis, resulting $A$ high relationship between variables is evident, thus developing a preliminary model based on engineering in the process of improving lifestyles through the Deming cycle and based on the S curve of innovation, hand in hand with technology and motivation.
\end{abstract}

\section{Introduction}

Changes in lifestyle in recent years have negatively affected health, mainly in low and middle developed countries [1, 2, 3], poor quality of diet, sedentary lifestyle, and emotional stress can cause inflammation, oxidative stress, sympathetic activation, and contribute to obesity, together these factors can trigger or exacerbate hypertension, diabetes, dyslipidemia, and sleepdisordered breathing, which can lead to atherosclerosis and ultimately heart failure [4]. That is why investigations such as that of Gómez, Roca, Gili, García, and García [5], analyze that in a depressive scenario, an incorrect lifestyle is present; In addition, depression causes sleep disorders, loss of energy, low level of physical activity and with this increases the desire to eat junk food.

Thus, unhealthy lifestyles lead to the development of chronic diseases (CD) and premature death. 70\% of deaths worldwide are caused by CD [2]; North America and Latin America are among the first places worldwide in factors that promote $\operatorname{CD}[1,2,3]$. Although CDs impact people, it has consequences on the economic development and human capital of countries, mainly low-income countries, ranging from productivity to the costs generated by their treatment [6]

Mexico in particular is in the first places in obesity, overweight and diabetes worldwide and among the OECD countries [7], Sinaloa, Mexico is aligned to national statistics with $70 \%$ obesity

"Corresponding Author: Selene Tamayo Castro, selene.tamayo@hotmail.com and overweight in its population with age equal to or greater than 20 years, and Los Mochis, Sinaloa with a $72.5 \%$ prevalence of obesity and overweight, this factor being the cornerstone of the development of chronic diseases of greater affectation; The need and lack of effective guidance are evident, one that not only tries to raise awareness but is also effective enough to achieve positive change on a large scale.

There is a wide variety of studies that support the positive impact of exercise, good nutrition, adequate sleep schedules and quality of sleep, as well as the importance of the environment on both physical and mental health $[1-5,7]$, however, there is a gap in information regarding the application of these factors as a whole, even more so the implementation of strategic planning and disruptive innovation in the improvement of lifestyles.

For all the above, the objective of this article is the diagnosis and analysis of the lifestyle, chronic diseases, strategic planning, and disruptive innovation of young university students from the private sector, for the development of a disruptive strategic model.

The essence of the proposed solution of the problem in question is the diagnosis of the needs of the population and therefore the development of a model with planning and disruptive innovation applied to the prevention and control of chronic diseases, such as overweight, obesity, diabetes, and cardiovascular diseases, which allows young students to have an adequate balance between physical and mental health, helping them to have a better 
academic and work performance, but above all, a better quality of life.

\section{Theoretical foundations}

\subsection{Strategic model}

According to the Royal Spanish Academy, the word model, coming from Italian, is an archetype or point of reference to imitate or reproduce it, differently, the strategy, the "Latin strategīa" is the art, traces to direct a matter [8].

On the other hand, strategy, coming from the war trade, is defined as the art of drawing to direct an issue, in an adjustable process, a set of rules that ensure an optimal decision at all times [8].

Deming Cycle, the cycle of continuous improvement for development, through the factors: plan, do, verify, and act that incorporated feedback and observation of uninterrupted practice [9].

\subsection{Disruptive innovation}

Disruptive innovation was defined for the first time by Christensen in 1997 as a process by which a product or service is brought to the market, through simple applications, to later win that market by displacing other competitors. The contribution of Master Christensen leads to disruptive innovation to break the status quo of companies or any industry. Likewise, Sartor in 2017 commits that disruptive technology is any that can deeply affect a sector of activity and its value chain; Disruptive innovation can be implemented in three areas, such as: disruptors in the improvement of a process, a change of product or business model [10].

\subsubsection{S-Curve pattern of innovation}

The model S-Curve of innovation Figure 1, helps to evaluate in which stage of the life cycle the technology is and provides an indicator of the maturity of the industry. Method used to locate what has been the behavior of a certain trend in the past and extrapolate it to the possible future as a guide.

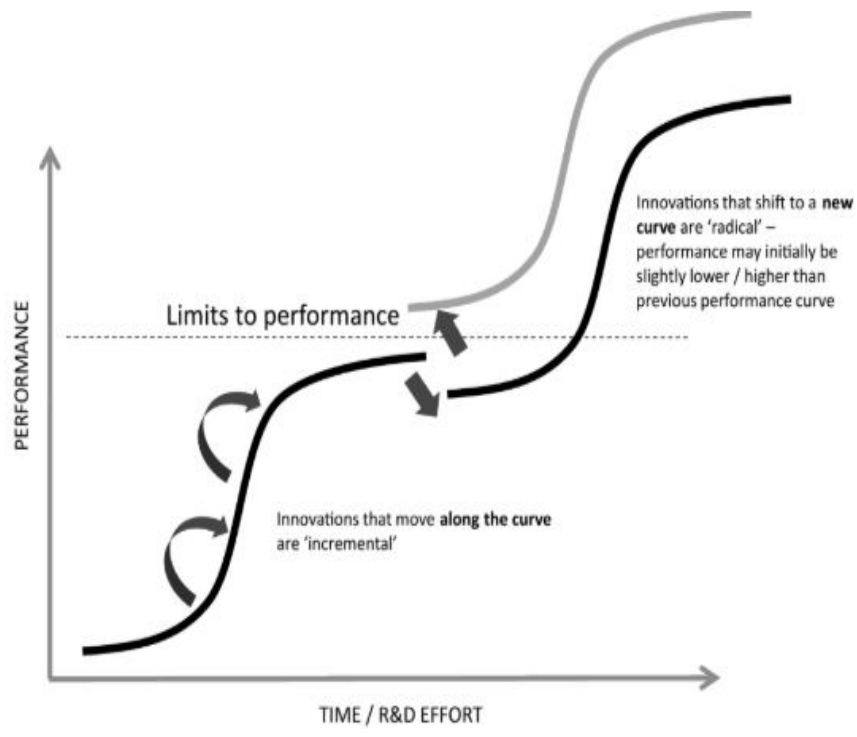

Figure 1: S-Curve of innovation

\subsection{Lifestyle}

Lifestyle is the set of behaviors that a specific individual puts into practice in a consistent and sustained way in their daily life and that can influence the maintenance of their health or places them at risk for disease: inadequate diet, activity poor physics, disturbed sleep-wake cycles, excessive consumption of substances and toxic habits, poor stress management, etc., are expressed in specific individual behaviors that are interpreted as risk factors, or behaviors that are shared by a group of people in a specific context [11].

Describing the sociodemographic, psychosocial, quality of life and educational variables in young university students and their relationship between them, as well as the ideal diet and habits based on the variables mentioned, are essential in a healthy lifestyle [12].

\subsection{Chronic diseases}

Chronic diseases (CD) account for new epidemics in developed societies, being link through conditions and lifestyles [3]

In Latin America, the main chronic diseases are obesity, cardiovascular diseases, cancer, chronic respiratory diseases, diabetes and arthritis are the main ones; Along the same lines, in Mexico the most prevalent chronic diseases are: obesity, arterial hypertension, diabetes, metabolic syndrome, fatty liver, chronic kidney disease [1].

\section{Methodology}

The present study was approached with a methodology focused on Hernández and Mendoza [13], being a quantitative investigation, with a scope according to the level of knowledge obtained with said investigation: descriptive - correlational.in the paper.

\subsection{Sample selection}

The first step focused on determining the population, defining as population young people from private universities located in Los Mochis, Sinaloa, 3,898 young people according to figures from the interactive educational statistics consultation program by the Ministry of Public Education.

To determine the size of the sample, the STATS 2.0 program was used, obtaining the amount of 350 as the sample size, results shown in Table 1. The sample is considered simple random probabilistic, since it can be answered by any student who is in the unit of analysis. The unit of analysis was represented by university students from the private sector, located in Los Mochis, Sinaloa.

Table 1: Characteristics of the sample
Characteristics

Universe size

Maximum acceptable error

Estimated percentage of the sample

Desired level of confidence

Sample size

\section{Number value/ percentage}

3,898

$5 \%$

$50 \%$

$95 \%$

350 


\subsection{Instrument design}

A quantitative measurement instrument was applied through the use of a structured questionnaire. The information collected was explicitly and standardized. The questionnaire used was of our elaboration. On the other hand, the degree of validity was determined through content and construct, the first based on impact literature, and the second through Pearson's correlation.

The scale used in the questionnaire was of the Likert type [14], made up of 5 points, which range from totally agree to totally disagree, determining its degree of reliability using Cronbach's Alpha.

The instrument consists of a total of 65 items divided by variables and dimensions. It should be noted that the degree of reliability of the instrument was measured through the application of the questionnaire, whose results were tabulated, and the calculation of the degree of reliability was generated using Cronbach's Alpha, using SPSS in Version 27, resulting 0.944, consequently demonstrating its excellent reliability to be applied.

Structured questionnaire in 5 sections, as follows:

- Section 1, diagnosis to identify the respondent's framework, 5 items.

- Section 2, lifestyle (EV), 13 items.

- Section 3, chronic diseases (CD), 16 items.

- Section 4, disruptive innovation (ID), 9 items.

- Section 5, strategic planning (SP), 22 items.

The scale used in the questionnaire consists of 5 points that go from totally disagree (1) to totally agree (5), as shown in Table 2.

Table 2: Instrument coding

\begin{tabular}{ll}
\hline \multicolumn{1}{c}{ Value } & \multicolumn{1}{c}{ Meaning } \\
1 & Strongly disagree \\
2 & Disagree \\
3 & Neither agree nor disagree \\
4 & Agree \\
5 & Strongly agree \\
\hline
\end{tabular}

It should be noted that two of the items are open questions.

\section{Hypothesis}

Applying strategic planning and innovation to the model potentiates the improvement of lifestyles from the health perspective of young university students.

\section{Results}

\subsection{Descriptive results}

Below are the results obtained from the structured survey, 350 responses received per application to the unit of analysis; $75 \%$ of the respondents were women (264), the remaining $25 \%$ were men (86).

Other research results are introduced below; The information is of a descriptive statistical nature of the set of variables extracted from the questionnaire, which allows us to know some characteristics of the sample.
Table 3: Responses with the most impact in affirmation regarding the strategic planning block

\begin{tabular}{lc}
\hline \multicolumn{1}{c}{ Strategic planning } & Percentage \\
\hline & $\begin{array}{c}\text { Strongly } \\
\text { agree/ agree }\end{array}$ \\
\hline $\begin{array}{l}\text { I am interested in an initiative that motivates young people in } \\
\text { the vocational and professional education stage to lead a } \\
\text { healthier life. }\end{array}$ & $86.86 \%$ \\
$\begin{array}{l}\text { An initiative that aims to be a leader in the country in terms } \\
\text { of reducing chronic diseases and improving lifestyles } \\
\text { interests me. }\end{array}$ & $87.43 \%$ \\
$\begin{array}{l}\text { I need to be advised by experts in nutrition, physical and } \\
\text { psychological health, who offer me plans that adapt to my } \\
\text { objectives and goals. }\end{array}$ & $76.57 \%$ \\
$\begin{array}{l}\text { Including innovation and creativity in my lifestyle enhances } \\
\text { my development }\end{array}$ & $84.57 \%$ \\
$\begin{array}{l}\text { A clean and organized infrastructure format makes it easier } \\
\text { for me to choose whether or not to join the initiative either } \\
\text { online or in person. }\end{array}$ & $76.57 \%$ \\
\hline $\begin{array}{l}\text { Having employees trained and frequently evaluated in quality } \\
\text { aspects, leadership fosters excellent services. }\end{array}$ & $89.14 \%$ \\
\hline $\begin{array}{l}\text { Constant updating of specialists to know and implement the } \\
\text { nost ing }\end{array}$ & $86.86 \%$ \\
\hline
\end{tabular}

most innovative and innovative work methods of the organization.

It is desirable to find clean and tidy areas when attending $\quad 91.43 \%$ training.

Having certifications in health and organizational hygiene generates a substantial attraction to the initiative.

Knowing that employees are properly compensated let me know that I am part of an organization with values.

Having a collaborative environment within the organization generates security for staff.

A safe work environment encourages a diversity of thoughts, thus generating creative ideas.

Having teams for collaboration motivates a mindset of social contribution.

Knowing the strengths and weaknesses of the organization allows us to foresee errors or failures of the plans, under or to be developed.

In the application of high-level programs, the value of the organization is perceived.

Establishing controls and administration generates flexibility to adapt to the organization.

Offering a periodic evaluation to collaborators allows maintaining constant development and verification of alignment to the objectives.

Having relationship programs with different communities generates cultural enrichment, therefore a range of ideas for the development of new training and motivation methods.

Establishing responsibilities and objectives for each position correctly empowers each employee in their area of expertise.

The table above represents the frequencies and percentages of the responses with an opinion of "Totally agree and agree" it could be observed in the first instance, referring to the strategic planning block, that there is a statement by $90 \%$ of the participants regarding interest for belonging to an organization or initiative with a safe work environment, which is aligned with the generation of ideas and offering excellent customer service, in turn, they claim to want a clean physical and online format, constant evaluation, and training of collaborators with the most novel and innovative in order to apply it to work methods and improvement of results, this hand in hand with relationship programs with various communities 
generating a range of ideas for the development of new methods of training and motivation, within a collaborative work environment, generating in turn security to staff.

Regarding the block of disruptive innovation Table-4, 90.86\% of the participants in the survey affirm that a change in lifestyle is possible through smart spaces and health monitoring, hand in hand with the accessibility of support from experts and price range for a greater reach and impact, in turn, more than $80 \%$ affirm their interest in prevention and control computer sessions in terms of the health approach and the extension of these extensive advantages both to face-to-face format and online (in- place / at-home).

Table 4: Responses with the most impact weight in affirmation regarding the disruptive innovation block

\begin{tabular}{lc}
\hline \multicolumn{1}{c}{ Disruptive innovation } & Percentage \\
\hline \multicolumn{1}{c}{$\begin{array}{c}\text { Strongly agree/ } \\
\text { agree }\end{array}$} \\
$\begin{array}{l}\text { I would like to be part of an organization with new } \\
\text { ideas to achieve my physical and psychological } \\
\text { goals. }\end{array}$ & $72.00 \%$ \\
$\begin{array}{l}\text { Smart spaces and health monitoring allow } \\
\text { generating a lifestyle change. }\end{array}$ & $90.86 \%$ \\
$\begin{array}{l}\text { In-place/at-home training products or features } \\
\text { create an extension of possibilities for club/gym } \\
\text { members }\end{array}$ & $74.86 \%$ \\
$\begin{array}{l}\text { Having the possibility of improving my lifestyle } \\
\text { in an accessible way allows me to prevent chronic } \\
\text { diseases. }\end{array}$ & $90.86 \%$ \\
$\begin{array}{l}\text { Having options for different ranges opens the } \\
\text { possibilities for a substantial number of people to } \\
\text { join the initiative to improve their lifestyle. }\end{array}$ & $82.29 \%$ \\
$\begin{array}{l}\text { I feel identified with an organization that sees the } \\
\text { human being as a whole and enhances their } \\
\text { development from the psychological, physical, } \\
\text { and spiritual approach. }\end{array}$ & $72.57 \%$ \\
$\begin{array}{l}\text { It is of interest to me to have at my disposal } \\
\text { computer sessions on prevention and health } \\
\text { control. }\end{array}$ & $80.57 \%$ \\
\hline
\end{tabular}

From the lifestyle block, it is resolved that the participants recognize there is a relationship between mind and body to achieve a state of well-being, $90 \%$ identify the consequences of an unhealthy lifestyle, however, only $56 \%$ affirm taking care of what eats and schedules, in addition to this $40 \%$ do not achieve their training objectives and consistency in them, on the other hand, there is a high rate of interest in doing physical activity $(76 \%)$, their interest is liable to the training of various or innovative disciplines methods that motivate them to achieve goals and improve their lifestyle.

Table 5: Responses with the most impact weight in affirmation regarding the lifestyle block

\begin{tabular}{lc}
\hline \multicolumn{1}{c}{ Lifestyle } & Percentage \\
\hline & $\begin{array}{c}\text { Strongly agree/ } \\
\text { agree }\end{array}$ \\
$\begin{array}{l}\text { I consider that a healthy mind inhabits a healthy } \\
\text { body. }\end{array}$ & $89.14 \%$ \\
$\begin{array}{l}\text { I identify the consequences of not maintaining a } \\
\text { healthy lifestyle. }\end{array}$ & $90.86 \%$ \\
$\begin{array}{l}\text { I am interested in doing physical activity that } \\
\text { improves my quality of life. }\end{array}$ & $76.57 \%$ \\
\hline
\end{tabular}

www.astesj.com
I identify the relationship between my mood and my diet.

Recognition of my efforts and achievements through rewards generates motivation to leave my comfort zone.

In Figure 2, the percentages of those participants who attend the gym, club, or classes for physical activity, and those who do not attend are presented, which is the main reason.

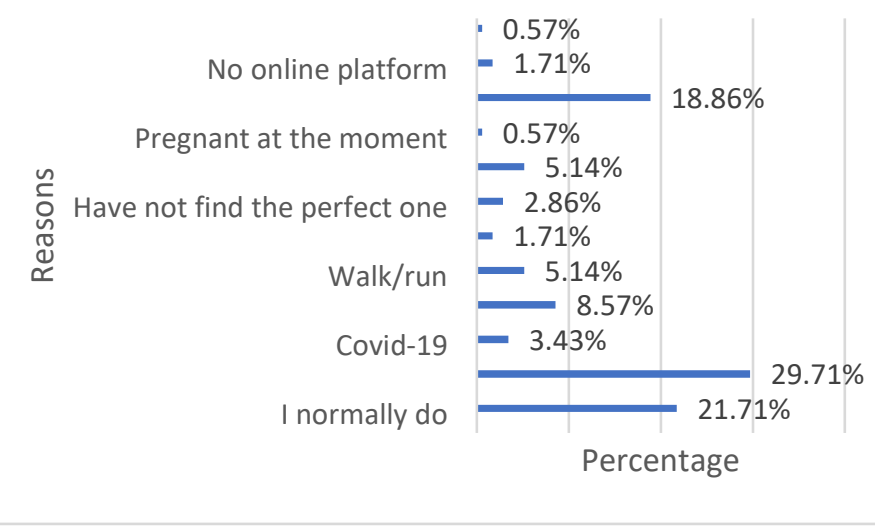

Figure 2: Percentages question EV-13

Regarding the chronic diseases block, the participants claim to be informed about the impact of obesity and overweight on their wellbeing, and later its reflection in a variety of chronic diseases, $92 \%$ consider it important to be informed of news and innovations against chronic diseases and maintain a health monitoring at least once a year.

Table 6: Responses with the most impact in affirmation regarding the block, chronic diseases

$\begin{array}{lr}\text { Chronic dieases } & \begin{array}{r}\text { Percentage } \\ \text { Strongly } \\ \text { agree/ agree }\end{array} \\ \begin{array}{l}\text { It is my knowledge that chronic diseases are } \\ \text { generally slow to develop, therefore my daily habits } \\ \text { make a big difference. }\end{array} & 92.86 \% \\ \begin{array}{l}\text { I consider it important to be informed of news and } \\ \text { innovations concerning chronic diseases. }\end{array} & 92.00 \% \\ \begin{array}{l}\text { Those who are overweight or obese have a higher risk } \\ \text { of developing chronic diseases. }\end{array} & 93.14 \% \\ \begin{array}{l}\text { I am informed of the causes and consequences of } \\ \text { being overweight or obese. }\end{array} & 93.71 \% \\ \text { I consider it important to carry out at least one annual } & 86.29 \%\end{array}$
health check-up.

It is important to highlight that the results of the open question CD-16 are presented in Figure 3; Of the 350 participants $94.4 \%$ affirm that one or more of their relatives suffer from one or more chronic diseases; it is important to highlight that this question had the possibility of selecting multiple answers; 590 answers were received, around $40 \%$ of the participants selected more than one chronic disease, placing diabetes in the first place, this information is of great value since those relatives of patients with type 2 diabetes mellitus tend to suffer from hypertension and overweight, the last one being the most recurrent in $63 \%$ of cases, providing strong signals of major diabetes awareness gaps among family members of patients living with type 2 diabetes mellitus [13]. 


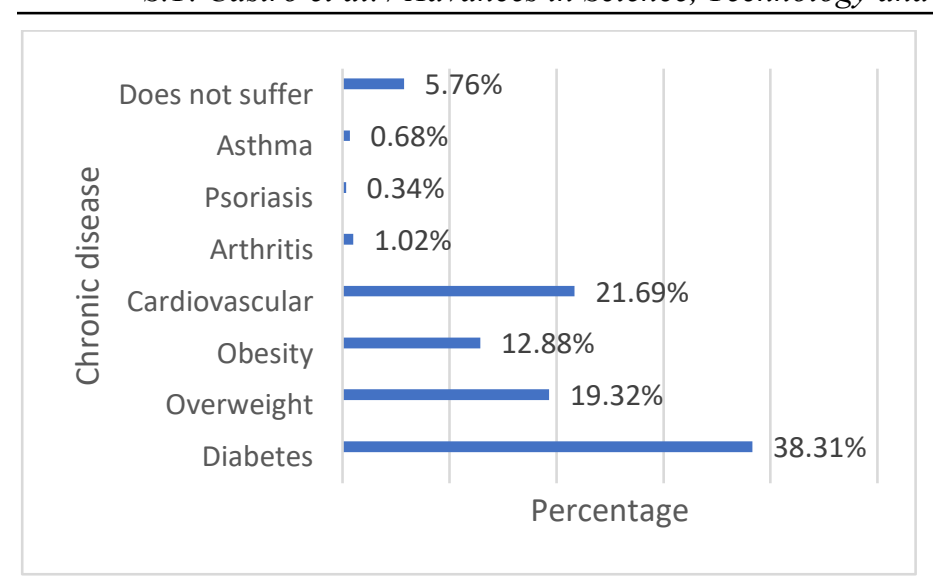

Figure 3: Percentages question CD-16

\subsection{Correlational results}

The reason for considering the correlation coefficient was to identify the strength of the relationship between variables strategic planning, disruptive innovation, lifestyle, and chronic diseases, in the positive sense; The results of Pearson's correlation are presented below in Table 7.

Table 7: Correlation of variables

\begin{tabular}{|c|c|c|c|c|c|}
\hline & & VI & VD1 & VD2 & VD3 \\
\hline \multirow[t]{3}{*}{ VI } & $\begin{array}{l}\text { Correlación de } \\
\text { Pearson }\end{array}$ & 1 &, $502^{* *}$ &, $592^{* *}$ &, $550^{* *}$ \\
\hline & Sig. (bilateral) & & ,000 & ,000 & ,000 \\
\hline & $\mathrm{N}$ & 350 & 350 & 350 & 350 \\
\hline \multirow{3}{*}{$\begin{array}{l}\text { VD } \\
1\end{array}$} & $\begin{array}{l}\text { Correlación de } \\
\text { Pearson }\end{array}$ &, $502^{* *}$ & 1 &, $557^{* *}$ &, $559^{* *}$ \\
\hline & Sig. (bilateral) & 000 & &, 000 & 000 \\
\hline & $\mathrm{N}$ & 350 & 350 & 350 & 350 \\
\hline \multirow[t]{3}{*}{$\begin{array}{l}\text { VD } \\
2\end{array}$} & $\begin{array}{l}\text { Correlación de } \\
\text { Pearson }\end{array}$ &, $592^{* *}$ & ,557 & 1 &, $783^{* *}$ \\
\hline & Sig. (bilateral) & 000 & ,000 & & ,000 \\
\hline & $\mathrm{N}$ & 350 & 350 & 350 & 350 \\
\hline \multirow[t]{3}{*}{$\begin{array}{l}\text { VD } \\
3\end{array}$} & $\begin{array}{l}\text { Correlación de } \\
\text { Pearson }\end{array}$ &, $550^{* *}$ &, $559^{* *}$ &, $783^{* *}$ & 1 \\
\hline & Sig. (bilateral) &, 000 & ,000 & ,000 & \\
\hline & $\mathrm{N}$ & 350 & 350 & 350 & 350 \\
\hline
\end{tabular}

Once the correlation between variables is carried out, the result is a moderate to high correlation, according to Tables 7 and 8 .

Table 8: Null-Correlation of variables

\begin{tabular}{|c|l|}
\hline Value & \multicolumn{1}{c|}{ Meaning } \\
\hline 0 & Null correlation \\
\hline 0.01 a 0.19 & Very low positive correlation \\
\hline 0.2 a 0.39 & Low positive correlation \\
\hline 0.4 a 0.69 & Moderate positive correlation \\
\hline 0.7 a 0.89 & High positive correlation \\
\hline 0.9 a 0.99 & Very high positive correlation \\
\hline 1 & Large and perfect positive correlation \\
\hline
\end{tabular}

Although the literature affirms the relationship between good habits and their impact on lifestyle improvement, the correlation found between innovation and strategic planning is key to promoting said improvement. It should be noted that university students do give importance to lifestyle care and chronic diseases, besides, they affirm feeling related to a well-established company and an excellent work environment, promoting development in the personal and social development of well-being, focused on their lifestyle improvement.

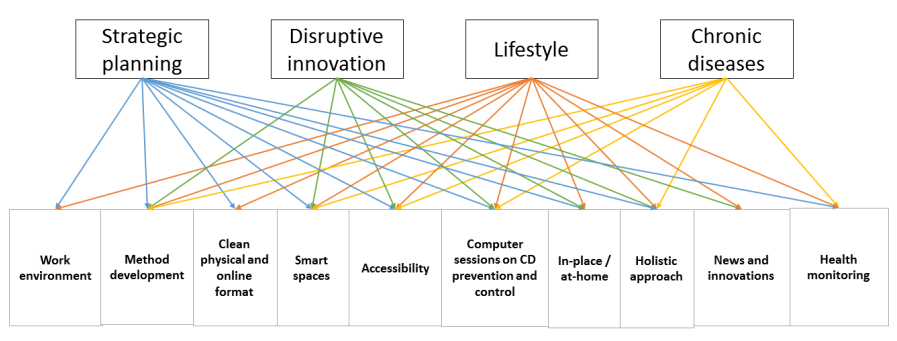

Figure 4: Correlation

Having said the above, what San Román indicates is confirmed, by saying that describing the sociodemographic, psychosocial, quality of life, and educational variables in young university students and their relationship between them, as well as diet and suitable habits, are essential in a healthy lifestyle [12].

\section{Disruptive strategic model}

After applying the instrument and collecting the data, a model was structured, which offers a holistic service for the detection of defects in the way in which the client interacts with the environment, causing health problems. After establishing a diagnosis, the strategic plan confirms that it generates the discipline to produce individual patterns that can be monitored by specialists, either in person or online in their respective areas, such as psychology, nutrition, and physical preparation, providing constant updating, training, and study of the innovations in their main areas of expertise.

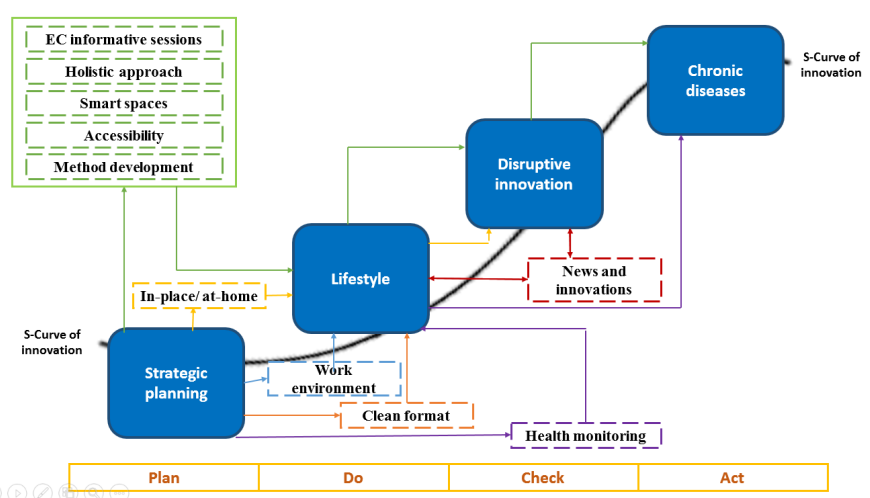

Figure 5: Correlation of variables model

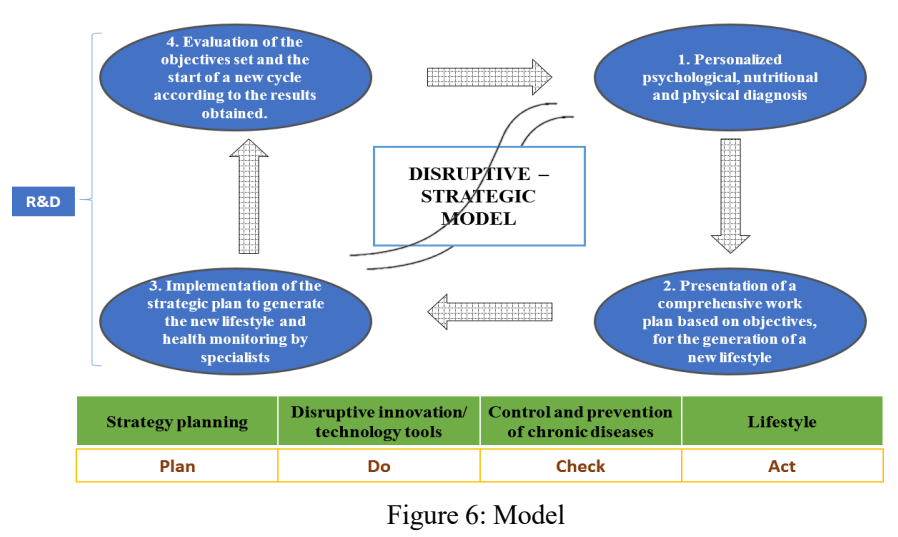


Figures 5 and 6, presents the proposed model based on the diagnosis and correlation previously carried out, implementing both the Deming cycle and the "S" of innovation throughout the "Strategic-disruptive model", in which those factors are present of greater correlation and need on the part of university students in terms of organizational structure, lifestyle, innovation and chronic diseases, generating a sequence of uninterrupted continuous improvement.

\section{Discussion}

An inclination for a clean format has been found, a collaborative environment which encourages security when generating ideas and proposing models or work methods based on research and innovation, this from the planning point of view and referring to the collaborators; on the other hand, inclusive programs, both speaking of cultures, as well as financial accessibility and outreach, highlighting the interest in staying informed of news and innovations in terms of lifestyle and chronic diseases, added to this a high rate of interest in stay motivated and generate consistency in lifestyle improvement; the above treating the human being from a holistic approach.

Aligned with Anderson and Fowers, it is confirmed that lifestyle behaviors, related to physical and mental health, generate the well-known hedonic well-being, which is based on satisfaction with life, positive emotions, and low negative emotions; that is, well-being and social interaction are intimately related, affecting the lifestyle of individuals, those who are more sociable tend to perform more physical activity and mental stability, they point out [15].

Likewise, what Leyton, Batista, and Castuera [6] analyze, the effects that motivational processes have on the adoption of lifestyle habits that enhance health in adolescents are confirmed; Describing the sociodemographic, psychosocial, quality of life and educational variables in young university students and their relationship between them, as well as the ideal diet and habits based on the aforementioned variables, are essential in a healthy lifestyle [7].

\section{Conclusions}

The objective of the study in this first phase of the research was to diagnose and generate a preliminary model with strategic planning and disruptive innovation applied to the prevention and control of chronic diseases for university students from the private sector.

The diagnostic and correlation study was carried out in the Los Mochis area, Sinaloa; The limitations of the study rely on reduced access to students due to the ongoing pandemic Covid 19, it is suggested for future studies to evaluate a greater number of areas, to measure the possibility of replication of the model in various geographical areas and/or its adaptability, either within or outside the country, extending the structured questionnaire referring to the current routine of the participants, current lifestyle, objectives, and the reason for them.

The strengths of the study lie in the generation of information regarding the needs of university students in the face of lifestyle improvement and the recognition of the correlation of the variables, this among all the four variables under study.

The hypothesis, applying strategic planning and innovation to the model, potentiates the improvement of lifestyles from the focus of youth health, it is demonstrated in terms of literature and diagnosis.

It is relevant to note that the result of this research is a preliminary model, which gives the guideline to develop the following phases of the present study, to implement and evaluate the final model, in consequence allowing a high rate of improvement in lifestyle at an early age in a broad social spectrum, positively impacting personal and social development at the moment and in the long term, shaping a more productive society.

\section{Conflict of Interest}

The authors declare no conflict of interest.

\section{References}

[1] B. Legetic, A. Medici, M. Hernández-Ávila, G. Alleyne, A. Hennis, Economic Dimensions of Noncommunicable Diseases in Latin America and the Caribbean, Pan American Health Organization, 2016.

[2] M. H Forouzanfar, A. Afshin, L. T Alexander, H R. Anderson, Z. A Bhutta, S. Biryukov, M. Brauer, R. Burnett, K. Cercy, F. J Charlson, et al. ., "Global, regional, and national comparative risk assessment of 79 behavioral, environmental and occupational, and metabolic risks or clusters of risks, 1990-2015: a systematic analysis for the Global Burden of Disease Study 2015" The Lancet, 388(10053), 1659-1724, 2016. doi.org/10.1016/S01406736(16)31679-8

[3] J. M. Mayoral, N. A. Sanz, P. Godoyc, M. J. Sierra, R. Cano, F. González, Á. Pousa, "Chronic diseases as a priority for public health surveillance in Spain" Gac Sanit, 30(2), 2016. doi.org/10.1016/j.gaceta.2015.12.008

[4] M. Aggarwal, B. Bozkurt, G. Panjrath, B. Aggarwal, RJ Ostfeld, ND Barnard, H. Gaggin, AM Freeman, K. Allen, S. Madan, et al., "Lifestyle Modifications for Preventing and Treating Heart Failure "Journal of the American College of Cardiology, 72(19), 2018. DOI: 10.1016 / j.jacc.2018.08.2160

[5] R. Gómez, M. Roca, M. Gili, J. García, M. García, "Healthy lifestyle: an undervalued protection factor against depression" Biological Psychiatry, vol 24, Issue 3, 2017, https://doi.org/10.1016/j.psiq.2017.10.004

[6] M. Leyton, M. Batista, R. Jiménez, "Prediction model of healthy lifestyles through the Theory of Self-determination of Physical Education students" Revista de Psicodidáctica, 25(1), 2020. doi: 10.1016 / j.psicod.2019.05.002

[7] F. Torres, A. Rojas, "Obesity and public health in Mexico: the transformation of the hegemonic pattern of food supply-demand", Problems of development, 49(193), 2018. doi.org/10.22201/ iiec.20078951e.2018.193.63185

[8] Royal Spanish Academy, "Dictionary of the Spanish language", edition 23, 2019.

[9] H. Schmidt, "Explosive precursor safety: An application of the Deming Cycle for continuous improvement," American Chemical Society, 26, 31-36, 2019. doi.org/10.1016/j.jchas.2018.09.005

[10] M. Borghino, Disruption: Beyond innovation, Grijalbo, 2018

[11] J. Grau, "Non-communicable chronic diseases: an approach from psychosocial factors", Salud \& Sociedad, 7(2), 2016 https://www.redalyc.org/pdf/4397/439747576002.pdf

[12] S. Roman, "Analysis of the profile of the university student in relation to healthy habits and lifestyles, motivations and socio-educational expectations", Doctoral thesis in education, University of Granada, 2018.

[13] R. Hernández-Sampieri, C. Mendoza, Research Methodology. The quantitative, qualitative, and mixed routes, Mc Graw Hill Education, 714, 2018.

[14] N. Urrunaga, JE Montoya, J. Jaime, M. Moscoso, MK Cárdenas, F. Diez, RH Gilman, A. Bernabe, "Attitudes, healthy lifestyle behaviors and cardiometabolic risk factors" Primary Care Diabetes, 2020. doi.org/10.1016/j.pcd.2020.07.003

[15] A. R. Anderson, B. J. Fowers, "Lifestyle behaviors, psychological distress and well-being: A daily diary study", Social Science \& Medicine, 263, 2020. doi.org/10.1016/j.socscimed.2020.113263 